\title{
$\mathrm{NaCl}, \mathrm{KCl}$, Potassium Lactate와 Calcium Ascorbate의 첨가가 저장 중 저염 돈육 패티의 이화학적 특성과 관능 특성에 미치는 영향
}

\author{
문성실 $^{1} \cdot$ 김영태 ${ }^{1 *}$ - 진상근 ${ }^{2} \cdot$ 김일석 $^{2}$ \\ '(주)선진 기술연구소, ${ }^{2}$ 진주산업대학교 동물소재공학과
}

\section{Effects of Sodium Chloride, Potassium Chloride, Potassium Lactate and Calcium Ascorbate on the Physico-chemical Properties and Sensory Characteristics of Sodium-reduced Pork Patties}

\author{
Sung Sil Moon ${ }^{1}$, Young Tae Kim ${ }^{1 *}$, Sang-Keun $\mathrm{Jin}^{2}$, and II-Suk Kim² \\ ${ }^{1}$ Sunjin Meat Research Center, Seoul 134-822, Korea \\ ${ }^{2}$ Department of Animal Resources Technology, Jinju National University, Jinju 660-758, Korea
}

\begin{abstract}
This study investigated the effects of sodium chloride, potassium chloride, potassium lactate and calcium ascorbate on the physico-chemical and sensory characteristics of sodium-reduced pork patties. Pork patties were prepared in 4 ways: T1 (control, $1.0 \% \mathrm{NaCl}), \mathrm{T} 2(0.6 \% \mathrm{NaCl}, 0.4 \% \mathrm{KCl}), \mathrm{T} 3(0.7 \% \mathrm{NaCl}, 0.3 \%$ potassium lactate) and $\mathrm{T} 4(0.7 \% \mathrm{NaCl}, 0.3 \% \mathrm{cal}-$ cium ascorbate). The $\mathrm{pH}$, cooking loss, total plate counts, TBARS (2-thiobarbituric acid reactive substances), surface color $(\mathrm{L}, \mathrm{a}, \mathrm{b})$ and sensory characteristics were evaluated. The partial substitution of $\mathrm{NaCl}$ with $\mathrm{KCl}$ and calcium ascorbate decreased the cooking loss and TBARS values, and enhanced microbial stability. The partial substitution of $\mathrm{NaCl}$ with potassium lactate significantly decreased TBARS values and enhanced microbial stability, but significantly increased cooking loss compared to the control after 1 and 4 days of storage. However, the surface color and sensory characteristics were not affected by any of the treatments.
\end{abstract}

Key words : $\mathrm{NaCl}$, sodium-reduced pork patty, lipid oxidation

\section{서 론}

$\mathrm{NaCl}$ 을 과잉 섭춰하게 되면 고혈압과 연계된 여러 심장 질환과 뇌졸중의 위험에 노출되게 된다. 이를 방지하기 위 해 세계보건기구(WHO, 1990)는 $\mathrm{NaCl}$ 의 일일 섭취량을 5 $6 \mathrm{~g}$ 으로 제한 할 것을 권장하고 있다. 하지만 여전히 많은 나라들에서 권장량 이상의 $\mathrm{NaCl}$ 을 섭취하고 있다(Ruusunen and Puolanne, 2005).

$\mathrm{NaCl}$ 이 건강상에 문제를 야기할 수 있음에도 식품 산업 에서 지속적으로 사용되고 있는 것은 식품의 저장성과 관 능적 특성에 중요한 역할을 하기 때문이다. 특히 육제품 에서 2.5-3.0\%가량 사용되고 있는 $\mathrm{NaCl}$ 은 수분과 지방의

*Corresponding author: Young-Tae Kim, Sunjin Meat Research Center, Kangdong, Seoul 134-822, Korea. Tel: 82-2-22250657, Fax: 82-2-471-9378, E-mail: meatlove77@hanmail.net
결합력을 증진시켜 가열 시에 안정적인 겔화를 유도하고 이로 인해 제품의 조직감을 좋게 한다(Terrell, 1983). 또한 육제품의 풍미를 강화하고(Gillette, 1985), 수분 활성도를 낮추어 보존성을 항상시키는 것으로 보고되고 있다(Marsh, 1983; Sofos, 1984). 반면 $\mathrm{NaCl}$ 의 사용을 줄이게 되면 육 제품의 조직감과 향미 그리고 저장성이 감소하게 된다 (Sofos, 1986). 이러한 이유로 육가공업자들은 육제품에 사 용되는 $\mathrm{NaCl}$ 의 수준을 줄이기 위한 방법으로 첨가량을 직 접 줄이거나, $\mathrm{KCl}, \mathrm{CaCl}_{2}, \mathrm{MgCl}_{2}$ 과 같은 다른 염으로의 대체, phosphate나 새로운 가공 기술의 도입 그리고 이 세 가지 방법들의 조합을 통해 육제품에 $\mathrm{NaCl}$ 의 첨가람을 줄 이고자 다방면으로 노력을 해 오고 있다(Sofos, 1984, 1986; Terrell, 1983).

분쇄 육제품에서 제품을 성형한 후 냉동시키는 방법은 $\mathrm{NaCl}$ 의 첨가 없이도 제품의 생산이 가능하게 하지만(Demos 등. 1994), $\mathrm{NaCl}$ 의 첨가는 조직감 증진, 풍미 강화 및 저 
장성 증진의 효과가 있기 때문에 여전히 0 에서 $2 \%$ 수준 에서 사용하고 있으나(Nielsen et al., 1995; Tseng et al., 2000 ), 대부분의 분쇄 육제품에서 $\mathrm{NaCl}$ 의 사용 수준을 $1 \%$ 이하로 낮게 유지하고 있다(Ruusunen and Puolanne, 2005).

Gelabert 등(2003)은 발효 소시지에 $\mathrm{NaCl}(2.6 \%)$ 의 일부 를 $\mathrm{KCl}$, potassium lactate 그리고 glycine으로 각각 10,20 , $30,40 \%$ 씩 대체하여 $\mathrm{NaCl}$ 의 첨가량을 줄이고자 하였다. 이 연구에 의하면 미생물에 대한 안정성을 확보할 수 있 었으나, $\mathrm{NaCl}$ 의 첨가량 대비 $\mathrm{KCl}$ 을 $40 \%(1.04 \mathrm{~g})$, potassium lactate와 glycine을 각각 $30 \%(0.78 \mathrm{~g})$ 와 $20 \%(0.52 \mathrm{~g})$ 이상 으로 대체할 경우 관능적 특성인 풍미와 조직감에 문제가 있다고 보고하였다. Cheng 등(2007)은 $\mathrm{NaCl}$ 을 $\mathrm{KCl}$ 로 25 , $33,50 \%$ 수준으로 각각 $0.5,0.66,1 \mathrm{~g}$ 으로 대체 하였을 때 돈육 패티의 적색도와 황색도 그리고 TBARS(2-thiobarbituric acid reactive substances)는 감소하였으나, 백색도와 $\mathrm{pH}$ 에는 영향을 주지 않는다고 하였다. Tan과 Shelef(2002) 는 냉동 및 냉장 분쇄 돈육에서 sodium lactate와 potassium lactate를 $2 \%(2 \mathrm{~g})$ 수준으로 첨가하면 미생물의 성장에 억 제 효과가 있고, $\mathrm{NaCl}$ 과 함께 혼합하여 사용하면 단독으 로 사용할 때보다 제품의 부패를 억제하는데 호과적이라 고 보고하였다. 국내의 경우 김 등(2006)은 $\mathrm{NaCl}$ 과 sodium tripolyphosphate 용액으로 마리네이드 처리한 돈육 등심의 품질 특성에 관한 연구에서 $\mathrm{NaCl}(10 \%)$ 의 단독 사용보다 $\mathrm{NaCl}(10 \%)$ 과 sodium tripolyphosphate $(3 \%)$ 의 혼합사용이 가열 감량을 유의적으로 낮추고 제품의 24 시간 $\mathrm{pH}$ 와 수 율 그리고 보수력을 유의적으로 높였다고 보고하였다 $(p<0.05)$.

따라서 본 연구는 건강 지향적 저염 돈육 패티 개발을 위해 첨가되는 $\mathrm{NaCl}$ 을 $\mathrm{KCl}$, potassium lactate, calcium ascorbate로 각각 $40 \%$ 와 $30 \%, 30 \%$ 로 대체하였을 때 돈육 패티의 이화학적 특성과 관능 특성에 미치는 영향을 알아 보고자 실시하였다.

\section{재료 및 방법}

\section{실험 재료 및 제품 제조}

본 실험에 사용한 저염 돈육 패티는 Table 1 의 배합비 를 바탕으로 제조하였다. 상업적으로 유통되고 있는 돼지 등심(M. longissimus dorsi)의 고기와 지방을 분리한 뒤 각 각을 $3 \mathrm{~mm}$ 플레이트로 분쇄하였다. 분쇄한 적육 $82.5 \%$ 대비 $\mathrm{NaCl} 1 \%$, B-pepper $0.3 \%$, 얼음물 $10 \%$ 을 넣고 30초 간 1 차 혼합한 후 ISP $0.5 \%$ 와 지방 $5 \%$, Olive oil $0.5 \%$ 및 Carageenan $0.2 \%$ 를 넣은 뒤 30 초간 2 차 혼합하고 $2 \mathrm{~cm}$ 두 께로 페티를 성형하여 대조구(T1, $\mathrm{NaCl} 1 \%)$ 로 삼았다. 처 리구는 대조구와 첨가방법 및 첨가량을 동일하게 하였으 며 $\mathrm{NaCl}$ 의 합량만을 조절하여 제조하였다. 처리구별로는 $\mathrm{T} 2(0.6 \% \mathrm{NaCl}, 0.4 \% \mathrm{KCl}), \mathrm{T} 3(0.7 \% \mathrm{NaCl}, 0.3 \%$ potas-
Table 1. Experimental design for examination

\begin{tabular}{|c|c|c|c|c|c|}
\hline \multirow{2}{*}{\multicolumn{2}{|c|}{ Ingredients(\%) }} & \multicolumn{4}{|c|}{ Treatments } \\
\hline & & \multirow{2}{*}{$\frac{\mathrm{T} 1^{13}}{82.5}$} & \multirow{2}{*}{$\frac{\mathrm{T} 2}{82.5}$} & \multirow{2}{*}{$\frac{\mathrm{T} 3}{82.5}$} & \multirow{2}{*}{$\frac{\mathrm{T} 4}{82.5}$} \\
\hline Pork ham & & & & & \\
\hline Fat & & 5.0 & 5.0 & 5.0 & 5.0 \\
\hline Olive oil & & 0.5 & 0.5 & 0.5 & 0.5 \\
\hline $\operatorname{ISP}^{2)}$ & & 0.5 & 0.5 & 0.5 & 0.5 \\
\hline Carageenan & & 0.2 & 0.2 & 0.2 & 0.2 \\
\hline \multirow{4}{*}{$\begin{array}{l}\mathrm{NaCl} \\
\text { replacement }\end{array}$} & $\mathrm{NaCl}$ & 1.0 & 0.6 & 0.7 & 0.7 \\
\hline & $\mathrm{KCl}$ & - & 0.4 & - & - \\
\hline & Potassium lactate & - & - & 0.3 & - \\
\hline & Calcium ascorbate & - & - & - & 0.3 \\
\hline B-pepper ${ }^{3)}$ & & 0.3 & & & \\
\hline Ice/water & & 10.0 & & & \\
\hline & Total & 100.0 & 100.0 & 100.0 & 100.0 \\
\hline
\end{tabular}

${ }^{11} \mathrm{~T} 1$ : control, treated with $1 \% \mathrm{NaCl}, \mathrm{T} 2$ : treated with $0.6 \% \mathrm{NaCl}$ and $0.4 \% \mathrm{KCl}, \mathrm{T} 3$ : treated with $0.7 \% \mathrm{NaCl}$ and $0.3 \%$ potassium lactate, $\mathrm{T} 4:$ treated with $0.7 \% \mathrm{NaCl}$ and $0.3 \%$ calcium ascorbate.

${ }^{2)}$ ISP : isolated soy protein.

${ }^{3)}$ B-pepper : Black pepper.

sium lactate)와 $\mathrm{T} 4(0.7 \% \mathrm{NaCl}, 0.3 \%$ calcium ascorbate)로 $\mathrm{NaCl}$ 의 일부를 대체하여 patty를 제조한 후 $0^{\circ} \mathrm{C}$ 에서 저장 하면서 분석에 사용하였다.

\section{$\mathrm{pH}$}

$\mathrm{pH}$ 는 시료 $3 \mathrm{~g}$ 을 증류수 $27 \mathrm{~mL}$ 와 함께 Homogenizer (T25B, IKA Sdn. Bhd., Malaysia)로 13,500 rpm에서 10초 간 균질 한 뒤 $\mathrm{pH}-m e t e r(8603, \mathrm{Metrohm}, \mathrm{Swiss})$ 로 측정하 였다.

\section{가열감량}

시료를 $200^{\circ} \mathrm{C}$ 전기오븐(TG 101-E, Fri-Jado Inc., Netherlands)에서 전후면 90초씩 가열하여 식힌 후 [(가열 전 시 료 무게 - 가열 후 시료 무게)/가열 전 시로 무게 * 100]의 식으로 가열 전후의 감량비를 계산하였다.

\section{총 미생물(aerobic plate counts)}

시료 $10 \mathrm{~g}$ 에 $0.1 \%$ 펩톤수 $90 \mathrm{~mL}$ (peptone: Difco Laboratories, Detroit, MI)를 넣은 뒤 2분 동안 스토마커(stomacher 400, Seward)를 이용하여 세균들을 용출하였다. 용 출된 용액은 펩톤수를 이용하여 적정하게 희석한 뒤, plate count agar(PCA, Difco)에 접종하여 $37^{\circ} \mathrm{C}$ 에서 24시간 배 양 측정하였다. 이 때 총 미생물수는 $\log \mathrm{CFU} / \mathrm{g}$ 로 기록하 였다.

\section{지질 산화}

지질 산화는 Buege와 Aust(1978)의 방법에 의해 시료 $5 \mathrm{~g}$ 에 butylated hydroxyanisole(BHA) $50 \mu \mathrm{L}$ 와 증류수 15 
$\mathrm{mL}$ 를 첨가하여 균질화시킨 후 균질액 $1 \mathrm{~mL}$ 를 시험관에 넣 고 여기에 $2 \mathrm{~mL}$ 2-thiobarbituric acid(TBA)/trichloroacetic $\operatorname{acid}(\mathrm{TCA})$ 혼합용액을 넣어 완전히 혼합한 다음, $90^{\circ} \mathrm{C}$ 의 항온수조에서 15 분간 열처리한 후 냉각시켜 $3,000 \mathrm{rpm}$ 에 서 10 분간 원심분리시켰다. 원심분리한 시료의 상층액 을 $531 \mathrm{~nm}$ 에서 홉광도를 측정하여 흡광도 수치에 5.88 을 곱하여 TBARS가로 계산하였다. 이때 TBARS는 $\mathrm{mg}$ malonadehyde $/ \mathrm{kg}$ 으로 표시하였다.

\section{육색}

육색은 Chroma meter(CR-400, Minolta Co., Japan)를 사 용하여 CIE L(명도, lightness), a(적색도, redness), b값(황 색도, yellowness)을 9회 반복 측정하여 표시하였고, 육색 측정에 사용된 표준색도판의 색도값은 $\mathrm{Y}=93.9, \mathrm{x}=0.3131$, $\mathrm{y}=0.3193$ 으로 하였다.

\section{관능 특성}

관능평가는 가열감량과 동일한 방법으로 가열한 시료를 잘 훈련된 관능검사요원 10 명을 선발하여 각 시헙구별로 9점 척도법으로 실시하였으며, 1점은 매우 나쁘거나 낮 음, 9점은 매우 좋거나 강함으로 짠맛, 쓴맛, 경도, 향미, 다즙성과 전체기호도에 대하여 평가하였다.

\section{통계분석}

아상의 실험에서 얻어진 결과는 SAS(1999)의 GLM(general linear model) 방법으로 분석하였고 처리 평균 간의 비교 를 위해 Duncan의 Multiple range test가 이용되었다.

\section{결과 및 고찰}

\section{$\mathrm{pH}$, cooking loss, 총 미생물수, TBARS}

$\mathrm{NaCl}$ 을 $\mathrm{KCl}(\mathrm{T} 2)$, potassium lactate(T3), calcium ascorbate(T4)로의 대체가 돈육 패티의 $\mathrm{pH}$, 가열감량, 총 미생 물수 및 TBARS 값에 미치는 영항은 Table 2에서 보는 바 와 같다.

$\mathrm{pH}$ 는 저장 초기에 처리구(T2, T3, T4)가 대조구에 비하 여 유의적으로 높은 값을 나타넸다 $(p<0.05)$. 처리구 간에 는 $\mathrm{T} 2$ 와 $\mathrm{T} 3$ 처리구가 각각 5.75 와 5.74 로 $\mathrm{T} 4$ 처리구 5.71 에 비하여 높은 경향이었으나 유의적인 차이는 없었으며 저장 8 일차에도 이와 유사한 경향이었다. 저장 기간에 따 른 $\mathrm{pH}$ 변화는 $\mathrm{T} 4$ 처리구에서 모든 기간에 걸쳐 유의적으 로 증가하는 것으로 나타났으며 $(p<0.05), \mathrm{T} 2$ 와 $\mathrm{T} 3$ 처리구 에서는 저장 4 일 이후 8 일까지 유의적으로 증가하였다 $(p<0.05)$. 그러나 대조구의 경우 저장 기간에 따른 차이는 나타나지 않았다. 이는 Cheng 등(2007)이 돈육 패티에 $\mathrm{NaCl}$ 첨가량 중 일부를 $\mathrm{KCl}$ 로 각각 $25(0.5 \mathrm{~g}), 33(0.66 \mathrm{~g})$, $50 \%(1 \mathrm{~g})$ 수준으로 대체 하였을 때 돈육 패티의 $\mathrm{pH}$ 에 영 향을 미치지 않았으며 저장기간 중에도 차이가 없었다는 보고와 다소 다른 경향으로 $\mathrm{KCl}$, potassium lactate, calcium ascorbate의 대체는 돈육 패티의 $\mathrm{pH}$ 에 영항을 미치는 것

Table 2. Effects of pH, Cooking loss, Total plate counts and TBARS values of sodium-reduced pork patties with different treatments during storage at $0^{\circ} \mathrm{C}$

\begin{tabular}{|c|c|c|c|c|}
\hline \multirow{2}{*}{ Items } & \multirow{2}{*}{ Treatments } & \multicolumn{3}{|c|}{ Storage (d) } \\
\hline & & 1 & 4 & 8 \\
\hline \multirow{4}{*}{$\mathrm{pH}$} & $\mathrm{T}^{1)}$ & $5.67 \pm 0.03^{b}$ & $5.75 \pm 0.04$ & $5.73 \pm 0.06^{b}$ \\
\hline & $\mathrm{T} 2$ & $5.75 \pm 0.01^{\mathrm{Ba}}$ & $5.77 \pm 0.02^{\mathrm{B}}$ & $5.85 \pm 0.02^{\mathrm{Aa}}$ \\
\hline & $\mathrm{T} 3$ & $5.74 \pm 0.01^{\mathrm{Ba}}$ & $5.74 \pm 0.02^{B}$ & $5.86 \pm 0.01^{\mathrm{Aa}}$ \\
\hline & $\mathrm{T} 4$ & $5.71 \pm 0.01^{\mathrm{Ca}}$ & $5.80 \pm 0.05^{\mathrm{B}}$ & $5.89 \pm 0.01^{\mathrm{Aa}}$ \\
\hline \multirow{4}{*}{ Cooking loss $(\%)$} & $\mathrm{T} 1$ & $16.64 \pm 2.23^{\mathrm{b}}$ & $14.20 \pm 0.23^{\mathrm{b}}$ & $16.93 \pm 2.02^{\mathrm{a}}$ \\
\hline & $\mathrm{T} 2$ & $14.59 \pm 1.64^{\mathrm{Bh}}$ & $14.01 \pm 0.36^{\mathrm{Bb}}$ & $17.11 \pm 0.47^{\mathrm{Aa}}$ \\
\hline & $\mathrm{T} 3$ & $20.94 \pm 0.86^{\mathrm{Aa}}$ & $16.83 \pm 0.80^{\mathrm{Ba}}$ & $18.06 \pm 1.16^{\mathrm{Ba}}$ \\
\hline & $\mathrm{T} 4$ & $15.35 \pm 1.36^{\mathrm{Ab}}$ & $13.52 \pm 0.16^{\mathrm{Bb}}$ & $14.20 \pm 0.25^{\mathrm{ABb}}$ \\
\hline \multirow{4}{*}{$\begin{array}{l}\text { Total plate counts } \\
(\mathrm{Log} \mathrm{CFU} / \mathrm{g})\end{array}$} & $\mathrm{T} 1$ & $3.77 \pm 0.01^{\mathrm{Ca}}$ & $3.84 \pm 0.03^{\mathrm{Ba}}$ & $4.01 \pm 0.03^{\mathrm{Aa}}$ \\
\hline & $\mathrm{T} 2$ & $3.53 \pm 0.07^{\mathrm{Bh}}$ & $3.57 \pm 0.08^{\mathrm{Bc}}$ & $3.83 \pm 0.04^{\mathrm{Ab}}$ \\
\hline & $\mathrm{T} 3$ & $3.63 \pm 0.06^{\mathrm{cb}}$ & $3.74 \pm 0.02^{\mathrm{Bb}}$ & $3.90 \pm 0.07^{\mathrm{Ab}}$ \\
\hline & $\mathrm{T} 4$ & $3.53 \pm 0.09^{\mathrm{Ch}}$ & $3.67 \pm 0.01^{\mathrm{Bb}}$ & $3.85 \pm 0.03^{\mathrm{Ab}}$ \\
\hline \multirow{4}{*}{$\begin{array}{c}\text { TBARS } \\
\text { (mg MA/kg) }\end{array}$} & $\mathrm{T} 1$ & $0.50 \pm 0.13^{\mathrm{Ba}}$ & $0.55 \pm 0.00^{\mathrm{Ba}}$ & $0.70 \pm 0.02^{\mathrm{Aa}}$ \\
\hline & $\mathrm{T} 2$ & $0.48 \pm 0.05^{\mathrm{a}}$ & $0.49 \pm 0.03^{b}$ & $0.56 \pm 0.02^{b}$ \\
\hline & $\mathrm{T} 3$ & $0.45 \pm 0.02^{\mathrm{Ba}}$ & $0.44 \pm 0.03^{\mathrm{Bb}}$ & $0.54 \pm 0.02^{\mathrm{Ab}}$ \\
\hline & $\mathrm{T} 4$ & $0.31 \pm 0.02^{\mathrm{Ch}}$ & $0.38 \pm 0.03^{B b}$ & $0.52 \pm 0.02^{\mathrm{Ab}}$ \\
\hline
\end{tabular}

1) $\mathrm{T} 1$ : control, treated with $1 \% \mathrm{NaCl}, \mathrm{T} 2$ : treated with $0.6 \% \mathrm{NaCl}$ and $0.4 \% \mathrm{KCl}, \mathrm{T} 3:$ treated with $0.7 \% \mathrm{NaCl}$ and $0.3 \%$ potassium lactate, $\mathrm{T} 4$ : treated with $0.7 \% \mathrm{NaCl}$ and $0.3 \%$ calcium ascorbate.

A-C Means with different superscripts in the same row significantly differ at $p<0.05$.

${ }^{a-b}$ Means with different superscripts in the same column significantly differ at $p<0.05$. 


\section{으로 나타났다.}

가열감량은 저장 기간 전반에 걸쳐 $\mathrm{T} 3$ 처리구가 대조구 (T1)와 다른 처리구들(T2, T4)에 비하여 높게 나타났다. 특 히 저장 1 일과 4 일에 $\mathrm{T} 3$ 처리구는 대조구와 다른 처리구 들(T2, T4)에 비하여 유의적으로 높은 감량을 보였다 $(p<0.05)$. 반면 $\mathrm{T} 2$ 와 $\mathrm{T} 4$ 처리구는 저장기간 전반에 걸쳐 $\mathrm{T} 3$ 처리구와 대조구(T1)에 비해 낮은 감량을 보였으나 유 의적인 차이는 없었다.

총 미생물수는 저장 기간 전반에 걸쳐 처리구(T2, T3, $\mathrm{T} 4)$ 가 대조구에 비하여 유의적으로 낮게 나타나 $(p<0.05)$, $\mathrm{KCl}$, potassium lactate, calcium ascorbate의 대체가 돈육 패티의 미생물 성장을 억제하여 주는 것으로 판단되었다. Gelabert 등(2003)은 발효 소시지에서 $\mathrm{NaCl}(2.6 \%)$ 을 $\mathrm{KCl}$, potassium lactate 그리고 glycine으로 각각 $40 \%(1.04 \mathrm{~g})$ 씩 대체 하였을 경우 발효 동안 $\mathrm{KCl}$ 과 glycine 처리구에서 총 미생물수의 유의적인 중가를 보였다고 하였으나 $(p<0.05)$, 본 연구에서 $\mathrm{KCl}$ 의 처리가 대조구에 비하여 유의적으 로 낮아 상이한 결과를 보였다. Tan과 Shelef(2002)는 potassium lactate의 lactate가 냉장 중 분쇄 돈육의 미생물 성장을 억제하여 준다고 하였으며, Knock 등(2006)도 lactate 의 사용은 beef rip steak의 미생물 성장을 억제하여 준다 고 하였다. 하지만 본 연구에서는 potassium lactate를 처리 한 $\mathrm{T} 3$ 처리구에서 저장 기간이 경과에 따라 유의적인 증 가를 보였다 $(p<0.05)$. 이것은 potassium lactate의 첨가량이 $0.4 \mathrm{~g}(0.4 \%)$ 로 $1.5 \mathrm{~g}(1.5 \%)$ 에서 $2 \mathrm{~g}(2.0 \%)$ 수준으로 처리한 다른 연구들에 비하여 낮았기 때문인 것으로 판단되었다.

식육 중 지질 산화의 척도로 사용되고 있는 TBARS 값 은 저장기간 전반에 걸쳐 대조구(T1)가 처리구들( $\mathrm{T} 2, \mathrm{~T} 3$, T4)에 비하여 높게 나타났다. 특히 저장 4 일과 8 일에 대
조구(T1)가 처리구들에 비하여 유의적으로 높게 나타나 $(p<0.05), \mathrm{KCl}$, potassium lactate, calcium ascorbate의 대체 는 돈육 패티의 지질 산화 방지에 도움을 주는 것으로 판 단되었다. T3 처리구에서 저장 4 일 0.44 (mg malonaldhyde/ $\mathrm{kg}), 8$ 일에 0.54 로 유의적인 증가를 보여 $(p<0.05)$, potassium lactate의 대체는 저장 초기 4일까지 지질 산화를 억제하 지만 그 이후의 효과는 미약한 것으로 판단되었다. T4 처 리구의 경우 저장 초기 다른 처리구들에 비하여 유의적으 로 낮은 TBARS 수치를 보인 반면 저장 기간이 경과에 따라 유의적인 차이를 보이며 증가하였다 $(p<0.05)$. Calcium ascorbate의 대체가 다른 처리구들에 비하여 저장 초기 지 질 산화 억제 작용이 있지만 저장 기간의 경과에 따른 지 질 안정성의 측면은 다른 처리구들에 비하여 떨어지는 것 으로 판단되었다. 반면 $\mathrm{T} 2$ 처리구의 경우 저장 기간의 경 과에 따른 TBARS 수치에 유의적인 차이를 보이지 않아 저장 중 지질의 산화를 억제해 주는 효과가 있는 것으로 판단되었다. Cheng 등(2007)이 돈육 패티에 $\mathrm{NaCl}(2 \%)$ 중 일부를 $\mathrm{KCl}$ 로 각각 $25 \%(0.5 \mathrm{~g}), 33 \%(0.66 \mathrm{~g}), 50 \%(1 \mathrm{~g})$ 수 준으로 대체 하였을 때 저장 초기에 대조구 $(\mathrm{NaCl} 2 \%)$ 에 비하여 $50 \%$ 대체구 $(\mathrm{NaCl} 1 \%, \mathrm{KCl} 1 \%)$ 에서 유의적으로 낮은 TBARS 값을 나타내었으나 $(p<0.05), 25 \%(\mathrm{NaCl} 1.5 \%$, $\mathrm{KCl} 0.5 \%)$ 와 $33 \%(\mathrm{NaCl} 1.34 \%, \mathrm{KCl} 0.66 \%)$ 에서는 유의 적 차이가 없었다고 보고하여 $0.4 \%(0.4 \mathrm{~g})$ 의 대체만으로도 지질 산화의 억제 효과를 보인 본 연구와 다소 다른 경향 을 보여 향후 $\mathrm{KCl}$ 의 첨가 수준 별 연구에 대한 보강 실 험이 필요 할 것으로 사료되었다.

\section{육색}

$\mathrm{NaCl}$ 을 $\mathrm{KCl}(\mathrm{T} 2)$, potassium lactate(T3), calcium ascor-

Table 3. Effects of $\mathrm{L}$, a and $\mathrm{b}$ of sodium-reduced pork patties with different treatments during storage at $0^{\circ} \mathrm{C}$

\begin{tabular}{|c|c|c|c|c|}
\hline \multirow{2}{*}{ Items } & \multirow{2}{*}{ Treatments } & \multicolumn{3}{|c|}{ Storage (d) } \\
\hline & & 1 & 4 & 8 \\
\hline \multirow{4}{*}{$\mathrm{L}$} & $\mathrm{T} 1^{11}$ & $53.81 \pm 2.24^{\mathrm{B}}$ & $54.92 \pm 0.71^{\mathrm{AB}}$ & $57.67 \pm 1.80^{\mathrm{A}}$ \\
\hline & $\mathrm{T} 2$ & $56.68 \pm 3.14$ & $55.30 \pm 1.23$ & $58.48 \pm 1.29$ \\
\hline & T3 & $57.51 \pm 0.60^{\mathrm{B}}$ & $56.69 \pm 1.02^{\mathrm{B}}$ & $59.05 \pm 0.42^{\mathrm{A}}$ \\
\hline & T4 & $55.75 \pm 1.05$ & $55.31 \pm 0.83$ & $56.87 \pm 1.23$ \\
\hline \multirow{4}{*}{ a } & $\mathrm{T} 1$ & $11.40 \pm 0.33^{\mathrm{A}}$ & $10.67 \pm 0.35^{\mathrm{Bb}}$ & $10.68 \pm 0.32^{\mathrm{B}}$ \\
\hline & $\mathrm{T} 2$ & $11.35 \pm 0.31^{\mathrm{A}}$ & $10.18 \pm 0.62^{\mathrm{Bab}}$ & $10.28 \pm 0.33^{\mathrm{B}}$ \\
\hline & $\mathrm{T} 3$ & $11.79 \pm 0.28^{\mathrm{A}}$ & $11.09 \pm 0.12^{\mathrm{Ba}}$ & $11.00 \pm 0.29^{\mathrm{B}}$ \\
\hline & $\mathrm{T} 4$ & $11.89 \pm 0.12^{\mathrm{A}}$ & $10.82 \pm 0.25^{\text {Bab }}$ & $10.27 \pm 0.51^{\mathrm{B}}$ \\
\hline \multirow{4}{*}{ b } & $\mathrm{T} 1$ & $7.77 \pm 0.38$ & $7.40 \pm 0.26$ & $7.88 \pm 0.09^{\mathrm{a}}$ \\
\hline & $\mathrm{T} 2$ & $8.11 \pm 0.61^{A}$ & $7.39 \pm 0.47^{\mathrm{B}}$ & $7.66 \pm 0.21^{\mathrm{Ba}}$ \\
\hline & $\mathrm{T} 3$ & $8.19 \pm 0.14$ & $7.89 \pm 0.48$ & $8.05 \pm 0.35^{\mathrm{a}}$ \\
\hline & $\mathrm{T} 4$ & $7.98 \pm 0.51^{\mathrm{A}}$ & $7.74 \pm 0.41^{\mathrm{AB}}$ & $7.15 \pm 0.07^{\mathrm{Bb}}$ \\
\hline
\end{tabular}

1) $\mathrm{T} 1$ : control, treated with $1 \% \mathrm{NaCl}, \mathrm{T} 2:$ treated with $0.6 \% \mathrm{NaCl}$ and $0.4 \% \mathrm{KCl}, \mathrm{T} 3:$ treated with $0.7 \% \mathrm{NaCl}$ and $0.3 \%$ potassium lactate, $\mathrm{T} 4:$ treated with $0.7 \% \mathrm{NaCl}$ and $0.3 \%$ calcium ascorbate.

${ }^{A-B}$ Means with different superscripts in the same row significantly differ at $p<0.05$.

${ }^{a-b}$ Means with different superscripts in the same column significantly differ at $p<0.05$. 
bate(T4)로의 대체가 돈육 패터의 명도(L), 적색도(a) 및 황 색도(b)에 미치는 영항은 Table 3 에서 보는 바와 같다.

명도는 $\mathrm{T} 3$ 처리구가 대조구(T1)와 다른 처리구들(T2, T4)에 비하여 다소 높은 값을 보였으나, 처리구간에 유의 적 차이는 없는 것으로 나타났다. 저장 기간이 경과함에 따라 부분적으로 유의적인 변화를 보이며 중가한 대조구 (T1)과 T3 처리구와 달리 $\mathrm{KCl}$ 과 calcium ascorbate를 처리 한 $\mathrm{T} 2$ 와 $\mathrm{T} 4$ 처리구에서 유의적인 변화는 없었다.
적색도는 potassium lactate를 처리한 $\mathrm{T} 3$ 처리구에서 저 장 4일에 대조구에 비하여 유의적으로 높은 적색도를 보 였지만 $(p<0.05)$, 전반적으로 처리구들 간에 큰 차이는 없 는 것으로 나타났다. 저장 기간의 경과에 따른 적색도의 변화는 대조구(T1)과 모든 처리구(T2, T3, T4)에서 저장 초기와 4 일 간에 유의적 차이를 보이며 감소하다가 $(p<0.05)$, 저장 4 일과 8 일 사이에는 유의적 차이를 보이지 않았다. 황색도는 명도의 변화와 대체로 반대의 경향을 보였다.

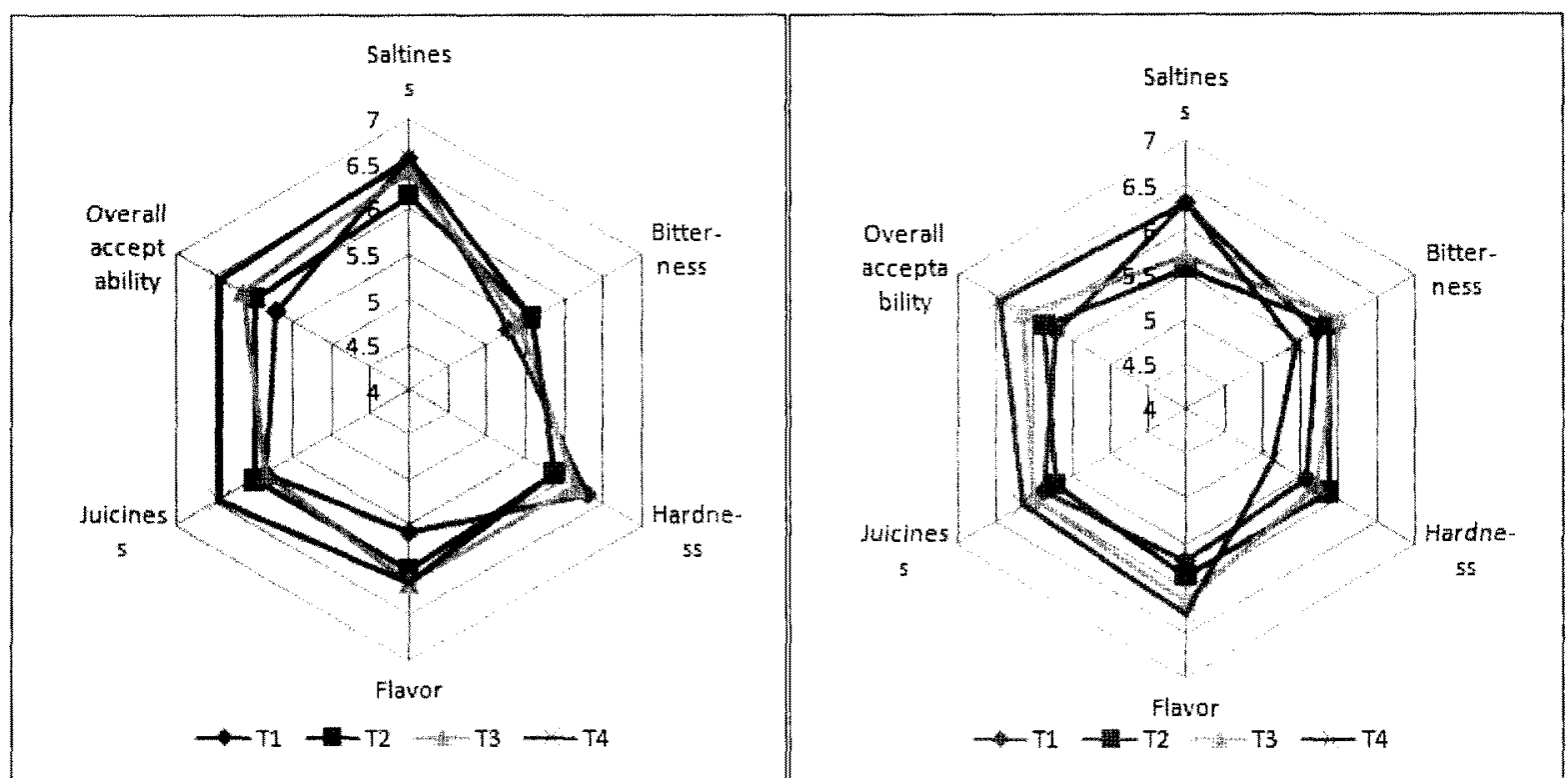

A B

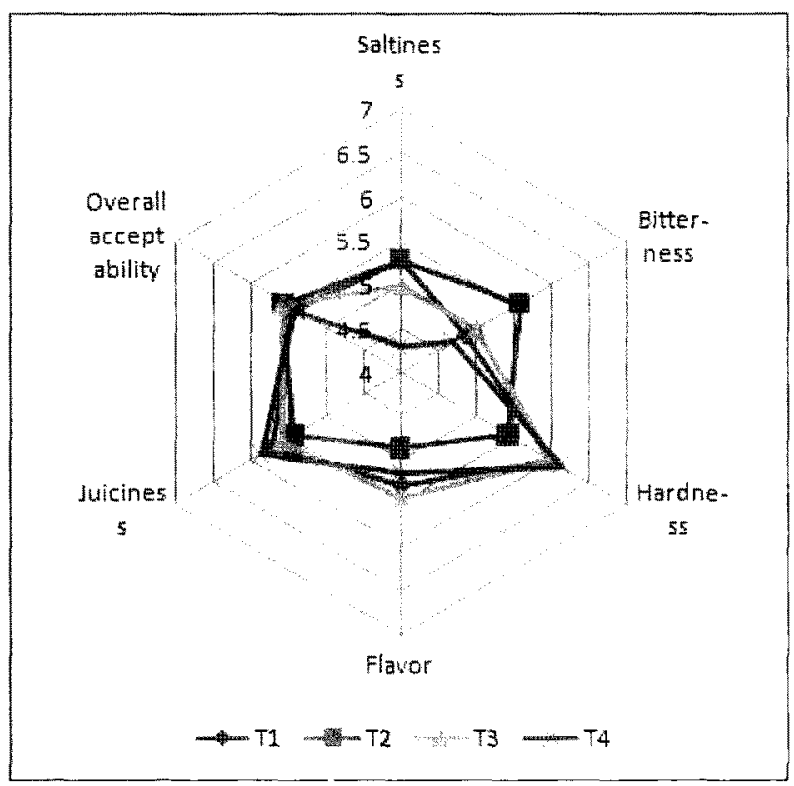

C

Fig. 1. Sensory characteristics of sodium-reduced pork patties with different treatments during storage at $0^{\circ} \mathrm{C}(\mathrm{A}: 1 \mathrm{~d}, \mathrm{~B}: 4 \mathrm{~d}, \mathrm{C}$ : 8 d). T1 : control, treated with $1 \% \mathrm{NaCl}, \mathrm{T} 2$ : treated with $0.6 \% \mathrm{NaCl}$ and $0.4 \% \mathrm{KCl}, \mathrm{T} 3:$ treated with $0.7 \% \mathrm{NaCl}$ and $0.3 \%$ potassium lactate, $\mathrm{T} 4$ : treated with $0.7 \% \mathrm{NaCl}$ and $0.3 \%$ calcium ascorbate. Saltiness, Bitterness : $1=$ not present, $9=$ very intense. Hardness, Flavor, Juiciness, Overall acceptability : $1=$ very bad, $9=$ very good. 
저장 기간의 경과에 따라 대체로 감소하는 경향이었으며, 저장 8 일에 $\mathrm{T} 4$ 처리구가 대조구(T1)와 $\mathrm{T} 2, \mathrm{~T} 3$ 처리구에 비하여 유의적으로 낮은 황색도를 보였다 $(p<0.05)$. 명도에 서 $\mathrm{T} 2$ 와 $\mathrm{T} 4$ 에서 저장 중 안정성을 유지한 반면 황색도에 서는 대조구(T1)과 $\mathrm{T} 3$ 처리구에서 안정성을 유지 하였다.

Cheng 등(2007)이 $\mathrm{NaCl}$ 중 일부를 $\mathrm{KCl}$ 로 $33 \%(0.66 \mathrm{~g})$ 와 $50 \%(1 \mathrm{~g})$ 수준으로 대체 하였을 때 저장 초기에 돈육 패티의 적색도와 황색도가 대조구 $(\mathrm{NaCl} 100 \%, 2 \mathrm{~g})$ 에 비 하여 유의적으로 낮았으며 $(p<0.05), 25 \%(0.5 \mathrm{~g})$ 대체 처리 구의 경우에 대조구와 처리구 간에 명도, 적색도 그리고 황색도 간에 유의적 차이가 없었다고 보고하였다. 이것은 본 연구에서 $\mathrm{KCl}$ 의 대체 수준 $40 \%(0.4 \mathrm{~g})$ 가 저장 초기 육 색에 영향을 주지 않는다는 분석과 일치하는 경향으로 나 타나 육색에 영향을 미치지 않는 범위 내에서 $\mathrm{NaCl}$ 의 첨 가 수준을 줄이고 $\mathrm{KCl}$ 로의 대체가 가능 할 것으로 판단 되었다.

\section{관능 특성}

$\mathrm{NaCl}$ 을 $\mathrm{KCl}(\mathrm{T} 2)$, potassium lactate(T3), calcium ascorbate(T4)로의 대체가 돈육 패티의 관능 특성에 미치는 영 향은 Fig. 1에서 보는 바와 같다.

짠맛은 저장 4일까지 대조구(T1)과 처리구들(T2, T3, T4) 사이에 유의적 차이는 없었으나, 저장 8 일에 대조구(T1)와 $\mathrm{T} 4$ 처리구가 각각 5.29 와 4.29 로 T4 처리구가 유의적으로 낮게 나타났다 $(p<0.05)$. 전체기호도는 저장 4 일에 대조구 (T1)와 T2 처리구에 비하여 $\mathrm{T} 4$ 처리구가 유의적으로 높 은 기호도를 보였다 $(p<0.05)$. 그러나 다즙성, 풍미, 조직감 및 쓴맞에 유의적인 차이는 없는 것으로 나타나, $\mathrm{NaCl}$ 을 $\mathrm{KCl}$, potassium lactate와 calcium ascorbate으로 대체 하였 을 때 관능적 특성에 큰 영향을 미치지 않는 것으로 판단 되었다.

Gelabert 등(2003)이 발효 소시지에서 $\mathrm{NaCl}(2.6 \%)$ 을 $\mathrm{KCl}$, potassium lactate 그리고 glycine으로 각각 $40 \%(1.04 \mathrm{~g})$ 씩 첨가하면 풍미와 조직감에 문제를 야기할 수 있다는 보고 와는 다른 경향이었으며, $\mathrm{Hand}$ 등(1982)이 $\mathrm{NaCl}$ 을 $\mathrm{KCl}$ 로 대체하여 제조된 재구성 돈육을 roasting 시 수분과 조직 감에 변화를 주지 않으나, 이춰를 생산하여 기호성을 떨 어뜨리는 원인이 된다는 결과와도 다소 차이가 있는 것으 로 나타나, 저염 돈육 패티에서 $\mathrm{NaCl}$ 을 $\mathrm{KCl}$, potassium lactate와 calcium ascorbate로 각각 $40 \%(0.4 \mathrm{~g}), 30 \%(0.3 \mathrm{~g})$, $30 \%(0.3 \mathrm{~g})$ 씩 대체가 가능하나, 그 이상 첨가하고자 할 때 는 대체량에 대한 검토가 필요 한 것으로 사료되었다.

\section{요 약}

본 연구는 돈육 패티 제조 시 첨가되는 $\mathrm{NaCl}$ 의 일부를 $\mathrm{KCl}$, potassium lactate, potassium lactate 및 calcium ascorbate로 각각 $40 \%, 30 \%, 30 \%$ 대체하였을 때 돈육 패 티의 이화학적 특성과 관능 특성에 미치는 영향을 구명하 고자 실시하였다. $\mathrm{NaCl}$ 을 $\mathrm{KCl}$ 과 calcium ascorbate로 대체 하였을 때 제조된 돈육 패터의 가열감량을 줄이고 지방 산화와 미생물의 성장을 억제하였으며, 색과 관능적 특성 에는 영향을 미치지 않는 것으로 나타났다. 이러한 결과 는 저염 육제품의 개발 시 $\mathrm{NaCl}$ 의 대체제로서 $\mathrm{KCl}$ 과 calcium ascorbate의 사용이 가능할 것으로 판단되었다. 하 지만 potassium lactate는 지질 산화와 미생물의 성장 억제 효과가 있었고 육색과 관능적 특성에 영향을 주지 않았으 나, 가열감량이 저장 초기와 4일에 대조구와 다른 처리구 들에 비해 유의적으로 높게 나타나 $\mathrm{NaCl}$ 의 대체제로 사 용하기 위해서는 첨가량을 조절할 필요가 있는 것으로 사 료되었다.

\section{참고문헌}

1. Buege, J. A. and Aust, J. D. (1978) Microsomal lipid peroxidation. Methods Enzymol. 52, 302-308.

2. Cheng, J. H., Wang, S. T., and Ockerman, H. W. (2007) Lipid oxidation and color change of salted pork patties. Meat Sci. 75(1), 71-77.

3. Demos, B. P., Forrest, J. C., Grant, A. L., Judge, M. D., and Chen, L. F. (1994) Low-fat, no added salt in restructured beef steaks with various binders. J. Muscle Foods 5, 407-418.

4. Gelabert, J., Gou, P., and Arnau, J. (2003) Effect of sodium chloride replacement on come characteristics of fermented sausages. Meat Sci. 65(2), 833-839.

5. Gillette, M. (1985) Flavor effects of sodium chloride. Food Technol. 39, 47-52, 56.

6. Hand, L. W., Terrell, R. N., and Smith, G. C. (1982) Effects of chloride salt, method of manufacturing and frozen storage in sensory properties of restructured pork roast. J. Food Sci. 47, 1771-1772.

7. Knock, R. C., Seyfert, M., Hunt, M. C., Dikeman, M. E., Mancini, R. A., Unruh, J. A., Higgins, J. J., and Monderen, R. A. (2006) Effects of potassium lactate, sodium chloride, sodium tripolyphosphate, and sodium acetate on colour, colour stability, and oxidative properties of injection-enhanced beef rib steaks. Meat Sci. 74(2), 312-318.

8. Marsh, A. C. (1983) Processes and formulations that affect the sodium content of foods. Food Technol. 37(7), 45-49.

9. Nielsen, G. S., Petersen, B. R., and Moller, A. J. (1995) Impact of salt, phosphate and temperature on the effect of a transglutaminace (FXIIIa) on the texture of restructured meat. Meat Sci. 41(3). 293-299.

10. Ruusunen, M. and Puolanne, E. (2005) Reducing sodium intake from meat products. Meat Sci. 70(3). 531-541.

11. SAS (1999) SAS/STAT Software for PC. Release 6.11, SAS Institute Inc., Cary, NC, USA.

12. Sofos, J. N. (1984) Antimicrobial effects of sodium and other ions in foods : a review. J. Food Saf. 6(1), 45-78.

13. Sofos, J. N. (1986) Use of phosphates in low-sodium meat 
products. Food Technol. 40(9), 52-64.

14. Tan, W. and Shelef, L. A. (2002) Effects of sodium chloride and lactates on chemical and microbiological changes in refrigerated and frozen fresh ground pork. Meat Sci. 62(1), 27-32.

15. Terrell, R. N. (1983) Reducing the sodium content of processed meats. Food Technol. 37(7), 66-71.

16. Tseng, T. F., Liu, D. C., and Chen, M. T. (2000) Evaluation of transglutaminase on the quality of low-salt chicken meatballs. Meat Sci. 55(4), 427-431.
17. WHO (1990) Diet, nutrition and the prevention of chronic diseases. Technical report series 797, Geneva.

18. Kim, I.-S., Jin, S.-K., Park, K.-H., Jung, G.-J., Kim, D.-H., Lee, M., Choi, J.-S., and Hoe, S.-K., Physicochemical properties of pork loin marinated with a $\mathrm{NaCl}$ and sodium tripolyphosphate solution and sensory attributes of tomato saucestewed products using marinated loin. Korean J. Food. Sci. Ani. Resour. 26(4), 411-417.

(2008.04.29 접수/2008.09.08 수정1/2008.11.05 수정2/ 